\title{
Cenplesto
}

\section{A ubiquidade das artes nos ambientes virtuais de contemplação: imergindo na Pinacoteca do estado de São Paulo}

\author{
Fábio Rogério Batista Lima \\ Mestre; Universidade Estadual Paulista Júlio de Mesquita Filho, Marília, SP, Brasil; \\ fabio.robal@yahoo.com.br \\ Plácida Leopoldina Ventura Amorim da Costa Santos \\ Doutora; Universidade Estadual Paulista Júlio de Mesquita Filho, Marília, SP, Brasil; \\ placida@marilia.unesp.br
}

\begin{abstract}
Resumo: As contínuas mudanças tecnológicas afetam diretamente as relações de trabalho, família, comunidade, nos quais o lugar e o espaço deixam de ser concretos e absolutos e passam a ser, segundo o pensador polonês Zygmunt Bauman, "líquidos e relativos". Estudamos o museu de artes Pinacoteca do Estado de São Paulo, a partir das heurísticas da Arquitetura da Informação Pervasiva (AIP). O estudo de caráter teórico e de nível descritivo e exploratório teve como base a observação sistemática qualitativa da bibliografia coletada. Como resultado, concluímos que as heurísticas da Arquitetura da Informação Pervasiva podem servir de subsídio na práxis de futuras elaborações de Arquitetura da Informação Pervasiva, direcionadas aos ambientes virtuais de contemplação das artes.
\end{abstract}

Palavras-chave: Museu. Arquitetura da informação. Arquitetura da informação pervasiva. Ubiquidade. Heurísticas.

\section{Introdução}

A tecnocultura é fruto da revolução tecnológica, e as ecologias informacionais complexas apresentam-se como resultados, sendo considerados, por Davenport (1998), como a integração de pessoas a sistemas informacionais complexos, artefatos tecnológicos de informação e comunicação em constante evolução. Essa ecologia transformou o modo de viver, fazer, pensar, representar, relacionar e comunicar dos indivíduos, devido ao acelerado processo de impregnação tecnológica em nossas vidas, “[...] interferindo tanto na subjetividade individual quanto na coletiva, criando entre elas uma 
Fábio Rogério Batista Lima, Plácida Leopoldina Ventura Amorim da Costa Santos.

interdependência e que favorece o surgimento de uma nova forma de ser e estar no mundo.” (SANTOS; VIDOTTI, 2009, não paginado). Nesse contexto, as "[...] tecnologias alteraram as maneiras pelas quais os consumidores interagem com as instituições centrais do governo, educação e comércio.” (RESMINI; ROSATI, 2011a, p. 3).

A mudança de antigas tradições (oral, escrita, visual) para a tradição digital vigente trouxe consigo um fenômeno global denominado, por Sáez Vacas (2007), de Rede Universal Digital (RUD). Esse é um conjunto heterogêneo de sistemas de redes (Internet, satélites, telefônicas, GPS, televisivas, etc.), cada vez mais digitais, que gera o que o autor chama de Novo Entorno Tecnossocial (NET).

A mudança em nossa forma de viver, atuar e relacionar, advinda desse novo entorno, fez com que surgisse uma nova forma de inteligência chamada por Sáez Vacas (2007) de Noomorfosis digital: uma inteligência pautada nas transições interpessoais, geradas pelos ambientes desterritorializados do ciberespaço, na nova captação e manejo da informação. Os indivíduos que transitam nesse espaço de comunicação de inteligência coletiva nasceram acostumados e familiarizados com esse entorno tecnossocial e, são denominados, por Sáez Vacas (2007), de nativos digitais.

Nesses ambientes, onde há uma nova arquitetura expositiva, nova forma de representação e disseminação de conteúdos informacionais ligados às artes, percebem-se o hibridismo $^{1}$ de linguagens e a criação da dualidade presencial/virtual que potencializa o vínculo entre o usuário e o local em que está inserido fisicamente (WEISSBERG, 2004).

As artes, neste contexto, estão imersas em um oceano de possibilidades criativo-estéticas, advindas das novas formas de construção, suporte e contemplação, possibilitadas por equipamentos informáticos conectados, o tempo todo, à Internet, juntamente com uma nova arquitetura das redes denominada AIP.

Segundo Lacerda (2015, p. 106), o conceito de AIP, proposto por Resmini e Rosati (2011a) em Pervasive Information Architecture, "[...] trata 
Fábio Rogério Batista Lima, Plácida Leopoldina Ventura Amorim da Costa Santos.

essencialmente do design de ecossistemas de informação em ecologias ubíquas." O ecossistema de informação é um complexo de pessoas, objetos e sistemas de informação conectados em toda parte, e todas as suas inter-relações em um espaço distinto (RESMINI; ROSATI, 2011a; LACERDA, 2015). O conjunto dos ecossistemas de informação e de suas relações formaria o que Resmini e Rosati (2011a) denominam ecologias ubíquas.

As ecologias ubíquas apresentam a característica de pervasividade da computação ubíqua e a natureza sistêmica e emergente da complexidade (RESMINI; ROSATI, 2011a; LACERDA, 2015). Nesse sentido, a computação ubíqua significa qualquer dispositivo de computação que, enquanto se move com a gente, é capaz de construir modelos, de forma dinâmica, de seus vários ambientes e configurar os seus serviços de acordo com eles (LYYTINEN; YOO, 2002).

No entanto, em meio a esse novo contexto, questiona-se como os museus estão lidando com a ubiquidade de seus acervos e com os serviços proporcionados pelas novas formas de disponibilizar o acesso à informação por meio de dispositivos móveis. Para encontrar resposta a essa questão, realizamos uma análise de um museu de arte situado no Brasil, que possui diferentes formas de disponibilizar o acesso a seus conteúdos informacionais, como, por exemplo, websites, catálogos impressos e visitas presenciais. Dessa forma, baseamo-nos nas heurísticas da AIP, apresentadas no livro Pervasive information architecture: designing cross channel user experiences (RESMINI; ROSATI, 2011a) e na tese de doutorado Arquitetura da informação pervasiva: contribuições conceituais (OLIVEIRA, 2014), para identificar quais elementos tidos como essenciais da AIP estariam contidos na arquitetura do site. O museu selecionado foi a Pinacoteca do Estado de São Paulo, por possibilitar o acesso a seu acervo também na versão digital.

O estudo é de caráter teórico, pois “[...] tem por objetivo ampliar generalizações, definir leis mais amplas, estruturar sistemas e modelos teóricos, relacionar e enfaixar hipóteses numa visão mais unitária do universo e gerar novas hipóteses por força de dedução lógica.” (OLIVEIRA, 1997, p. 123); de 
Fábio Rogério Batista Lima, Plácida Leopoldina Ventura Amorim da Costa Santos.

nível descritivo, por “[...] possibilitar as explicações das relações de causa e efeito dos fenômenos, ou seja, analisar o papel das variáveis que, de certa maneira, influenciam ou causam o aparecimento dos fenômenos." (OLIVEIRA, 1997, p. 123); e exploratório, na medida em que “[...] possibilita ao pesquisador fazer um levantamento provisório do fenômeno que deseja estudar de forma mais detalhada e estruturada, além da obtenção de informações acerca de um determinado produto." (OLIVEIRA, 1997, p. 135).

A pesquisa apresenta abordagem qualitativa, tendo como base a observação sistemática da bibliografia coletada, utilizando o suporte teórico da Ciência da Informação nas reflexões sobre as heurísticas da AIP aplicada ao domínio museológico, isto é, museu de artes.

Na próxima seção, apresenta-se a contextualização da Arquitetura da Informação (AI) e da AIP como uma das formas de abordagem da AI, rumo a um novo paradigma informacional e arquitetural. As mudanças nas correntes teóricas da AI geram diferentes abordagens, entre elas a da AIP, o que torna necessário um repensar da Ciência da Informação quanto à Arquitetura da Informação clássica.

\section{Arquitetura da Informação Pervasiva (AIP)}

Fazemos parte de um cenário no qual as contínuas mudanças tecnológicas afetam, diretamente, as relações de trabalho, de família e de comunidade, e no qual o lugar e o espaço deixaram de ser concretos e absolutos e passam a ser, segundo o pensador polonês Zygmunt Bauman (2003), "líquidos e relativos".

Para Santaella (2013, p. 133), “[...] espaços são os ambientes nos quais objetos e eventos ocorrem [...]; lugar é espaço investido de compreensão, de comportamento apropriado e de expectativas culturais." Para Castells (1999), o espaço “[...] é a expressão da sociedade, uma vez que nossa sociedade está passando por transformações estruturais [...]." Netto (2011) complementa essa percepção e afirma que "as novas redes digitais impactam as possibilidades da prática humana e sua relação com o espaço." Pois vivenciamos ambientes criados no ciberespaço, cada vez mais ligados às tecnologias móveis e que nos 
Fábio Rogério Batista Lima, Plácida Leopoldina Ventura Amorim da Costa Santos.

fazem repensar os espaços, sua legitimidade e o modo como às pessoas reencontram o espaço cotidiano.

No ciberespaço, “[...] qualquer informação e dados podem se tornar arquitetônicos e habitáveis, de modo que o ciberespaço e a arquitetura do ciberespaço são uma só e mesma coisa.” (SANTAELLA, 2007, p. 16-17). Isso vai de encontro a um dos princípios da Teoria Geral da Arquitetura da Informação (TGAI) que diz que "[...] todo espaço possui uma arquitetura subjacente, assim como a arquitetura da informação é inerente a qualquer espaço de informação.” (LIMA-MARQUES, 2011, p.161).

O termo "arquitetura", por sua vez, é definido, etimologicamente, por Cunha (2007, on-line) como:

\begin{abstract}
A arte ou técnica de projetar e edificar o ambiente habitado pelo ser humano"; "arte e técnica de organizar espaços e criar ambientes para abrigar os diversos tipos de atividades humanas, visando também à determinada intenção plástica"; "conjunto de princípios, normas, materiais e técnicas usados para criar o espaço arquitetônico"; e "conjunto de elementos que perfazem um todo; estrutura, natureza, organização.
\end{abstract}

O que diferencia, essencialmente, o espaço físico dos espaços informacionais é o fluxo de informações infinitamente configurável em termos de estruturação, tanto no aspecto do design quanto do próprio espaço de informação; ao contrário dos espaços físicos, de caráter mais estático e materializado (MCCAULEY, 2001; LACERDA, 2015). Ao comparar a Arquitetura tradicional com a Arquitetura da Informação, observa-se que ambas apresentam a mesma matéria-prima - o 'espaço' - e servem a necessidades humanas, mesmo que de natureza diversa (LACERDA, 2005).

A abordagem arquitetural, do início dos estudos voltados à Arquitetura da Informação (AI), teve como influência os trabalhos de Richard Saul Wurman em meados da década de 1960, quando ele já utilizava em seus livros a palavra “Arquiteto da Informação". Em 1976, o termo "Arquitetura da informação" foi utilizado por ele no evento American Institute of Architects Annual Meeting. Sendo assim, o termo Arquitetura da Informação foi definido, por ele, como a 
Fábio Rogério Batista Lima, Plácida Leopoldina Ventura Amorim da Costa Santos.

“[...] ciência e a arte de criar instruções para espaços organizados." (LACERDA, 2005, p. 99).

A abordagem sistêmica firmou-se por meio da Teoria Geral dos Sistemas e das demandas de criação de sistemas de informação para os contextos organizacionais entre as datas 1950 e 1968. Morville e Rosenfeld (2006) inserem, na AI, estudos clássicos da Ciência da Informação e da Biblioteconomia, que até hoje são aplicados em estudos de ambientes de informação digital da Web.

Essas mudanças foram importantes para o surgimento $\mathrm{e} o$ desenvolvimento da AIP, concebida por Resmini e Rosati (2011b) como uma abordagem voltada às questões relativas ao design de ecossistemas de informação em ecologias ubíquas. Pela definição dos autores:

Nós denominamos esses novos espaços estendidos de informação nos quais interagimos tanto com entidades digitais quanto físicas ecologias ubíquas: são sistemas que conectam pessoas, informações, processos, que estão em toda parte. São arquiteturas da informação pervasivas. São a camada estruturante que atravessa as diferentes mídias, canais e processos: na qual expressamos nosso eu expandido, socialmente (RESMINI; ROSATI, 2011a, p. xvi).

A AIP seria, segundo Lacerda (2015, p.23), “[...] uma subdisciplina da Arquitetura da Informação.” Já o termo pervasivo, na AIP, que trata dessas ecologias informacionais refere-se, primeiramente, à informação, por ela ser penetrante, por alastrar-se por vários tipos de ambientes e dispositivos tecnológicos e por moldar-se, constantemente, aos comportamentos dos sujeitos.

Tais ecologias também englobam as tecnologias de informação e comunicação "[...] e de todas as comunidades culturais a que elas dão origem e nelas se desenvolvem de acordo com os protocolos, práticas, instituições e poderes que lhes dão forma e as dinamizam." (SANTAELLA, 2013, p. 13).

Partimos da premissa de que a produção de conteúdos informacionais, atualmente, deverá adaptar-se ao potencial hipermídia, interativo e colaborativo das interfaces computacionais vigentes. A chegada de uma sociedade eletrônica de informação, segundo Barreto (2014), fez com que a delimitação do tempo e do espaço dos conteúdos se transformasse. 
Fábio Rogério Batista Lima, Plácida Leopoldina Ventura Amorim da Costa Santos.

Para que essa ação investigativa, a respeito da AIP, seja mais concisa, apresentaremos a seguir, o Quadro 1, com os elementos essenciais da AIP, baseado nas heurísticas de Resmini e Rosati (2011a) e ampliado por Oliveira (2014). Heurística, nesse sentido, “[...] é o conjunto de boas práticas de design relacionadas aos princípios, aplicáveis ao domínio em questão.” (LACERDA, 2015, p. 172).

Este quadro nos dá suporte conceitual para a compreensão da temática abordada. Nossa atenção está voltada para o conceito de 'ubiquidade', visto que é essa característica que será analisada nas artes disponíveis nos ambientes virtuais de exposição.

Quadro 1 - Atributos da arquitetura da informação pervasiva

\begin{tabular}{|c|c|}
\hline Atributo & Enunciado \\
\hline Status científico & $\begin{array}{l}\text { Abordagem teórica e prática da disciplina científica pós-moderna } \\
\text { Arquitetura da Informação. }\end{array}$ \\
\hline $\begin{array}{l}\text { Ecologia } \\
\text { informacional }\end{array}$ & $\begin{array}{l}\text { Conjunto de relações entrecruzadas de sujeitos, processos, estruturas } \\
\text { informacionais, estruturas tecnológicas, espaços, ambientes, canais, } \\
\text { dispositivos e quaisquer elementos pertencentes aos ambientes analógicos, } \\
\text { digitais ou híbridos. }\end{array}$ \\
\hline Complexidade & $\begin{array}{l}\text { Tecido interdependente, interativo e retroativo entre o objeto de } \\
\text { conhecimento e seu contexto, as partes e o todo, o todo e as partes e as } \\
\text { partes entre si. }\end{array}$ \\
\hline Pervasividade & $\begin{array}{l}\text { Capacidade ou tendência a propagar-se, infiltrar-se, difundir-se total ou } \\
\text { inteiramente por meio de vários meios, canais, sistemas, tecnologias, etc. }\end{array}$ \\
\hline Ubiquidade & $\begin{array}{l}\text { Capacidade de estar presente em todos os lugares ao mesmo tempo, } \\
\text { onipresença. }\end{array}$ \\
\hline Ever & $\begin{array}{l}\text { Tendência, fenômeno geral de convergência para o processamento da } \\
\text { informação dissolvida em meio aos comportamentos dos sujeitos. }\end{array}$ \\
\hline Place-making & $\begin{array}{l}\text { Capacidade de redução da desorientação, capacidade de construção do } \\
\text { sentido de localização na ecologia informacional complexa. }\end{array}$ \\
\hline Consistência & $\begin{array}{l}\text { Capacidade de atender as finalidades, os contextos e as pessoas para as } \\
\text { quais é projetado na ecologia informacional complexa. }\end{array}$ \\
\hline Resiliência & $\begin{array}{l}\text { Capacidade de moldar-se e adaptar-se a usuários específicos, necessidades } \\
\text { específicas e estratégias de busca contextuais. }\end{array}$ \\
\hline Redução & $\begin{array}{l}\text { Capacidade de gerenciar grandes conjuntos de informações e minimizar o } \\
\text { estresse e frustração associada com a escolha de um conjunto cada vez } \\
\text { maior de fontes de informação, serviços e produtos. }\end{array}$ \\
\hline Correlação & $\begin{array}{l}\text { Capacidade de sugerir conexões relevantes entre elementos de informação, } \\
\text { serviços e bens para ajudar os usuários a alcançar objetivos explicitados ou } \\
\text { estimular necessidades latentes. }\end{array}$ \\
\hline $\begin{array}{l}\text { Interoperabilidad } \\
\mathrm{e}\end{array}$ & $\begin{array}{l}\text { Capacidade de um sistema ou de partes de um sistema se comunicar e } \\
\text { trabalhar efetivamente no intercâmbio de dados ou informações com outro } \\
\text { sistema ou com outra parte do sistema, geralmente, de tipo diferente, } \\
\text { projetado e produzido de forma diferente. }\end{array}$ \\
\hline Semântica & $\begin{array}{l}\text { Processo de atribuição de significados, via linguagem, aos objetos e } \\
\text { fenômenos que nos são apresentados como realidade. }\end{array}$ \\
\hline Acessibilidade & Possibilidade e condição de alcance, percepção e entendimento para a \\
\hline
\end{tabular}


Fábio Rogério Batista Lima, Plácida Leopoldina Ventura Amorim da Costa Santos.

\begin{tabular}{|c|l|}
\hline & $\begin{array}{l}\text { utilização com segurança e autonomia de edificações, espaços, mobiliários, } \\
\text { equipamentos urbanos e elementos tecnológicos. }\end{array}$ \\
\hline Usabilidade & $\begin{array}{l}\text { Capacidade dos elementos da ecologia serem usados com eficiência, } \\
\text { eficácia e satisfação dos sujeitos. }\end{array}$ \\
\hline Encontrabilidade & $\begin{array}{l}\text { Processo que se situa entre as funcionalidades de um ambiente } \\
\text { informacional tradicional, digital ou híbrido e as características dos sujeitos. } \\
\text { Comporta desde a produção até a apropriação da informação e possibilita a } \\
\text { recuperação da informação por meio dos mecanismos de busca. }\end{array}$ \\
\hline
\end{tabular}

Fonte: Adaptado de Oliveira (2014, p. 158)

\subsection{Ubiquidade}

O termo ubiquidade enraíza-se, etimologicamente, no latim Ubiquitas, tendo ubique como componente que significa: que pode ter diversas localizações; que está ao mesmo tempo em toda parte; onipresente; que pode dividir-se ou existir em muitos pontos ao mesmo tempo; cuja projeção pode ser capturada de vários e diferentes lugares (ECKERT-HOFF, 2011). Na Teologia, emprega-se o termo ubiquidade para transmitir a ideia de onipresença, como aquilo que pode estar ao mesmo tempo em toda parte, como a ideia de Deus. A ubiquidade na informação, atualmente, é atrelada à computação ubíqua.

De acordo com Santaella, computação ubíqua colhe os benefícios dos avanços da computação móvel e da computação pervasiva. Ela surge “[...] da necessidade de se integrar mobilidade com a funcionalidade da computação pervasiva." (SANTAELLA, 2013, p.17). Para Resmini e Rosati (2011a, p. 18, tradução nossa), a computação ubíqua,

Refere-se à incorporação da computação em meio ambiente, objetos, eletrodomésticos, displays e sistemas, principalmente de maneira invisível. O termo é universalmente atribuído a Mark Weiser, que em 1991 escreveu um artigo intitulado "O computador para o século 21”, que foi publicado pela Scientific American. Em computação ubíqua, os usuários interagem com muitos diferentes dispositivos e sistemas, em diferentes lugares, com diferentes graus de consciência que eles estão usando ferramentas de informática. Computação difundida, ambientes inteligentes, coisas inteligentes, computação física, e Internet das coisas [...].

A informação é processada ao nosso redor, nos mais variados tipos de objetos e atividades diárias. No entanto, não podemos nos esquecer de que para pensarmos na ubiquidade, ou seja, "[...] o fato de que podemos finalmente ocupar dois lugares no espaço ao mesmo tempo, temos de considerar o advento 
Fábio Rogério Batista Lima, Plácida Leopoldina Ventura Amorim da Costa Santos.

de um espaço anteriormente inexistente na tessitura do mundo: o ciberespaço." (SANTAELLA, 2013, p. 134). Dessa forma, ambientes responsáveis por resguardar a herança cultural e artística, como os museus de artes, por exemplo, têm migrado cada vez mais para o mundo virtual e disponibilizado seus acervos para contemplação das artes em qualquer lugar, possibilitando aos usuários montarem seu roteiro de visitação e exposição, por meio das várias interfaces interativas que muitos museus têm, principalmente em países desenvolvidos.

\subsection{Ubiquidade e canais cruzados no universo museológico}

Nos últimos tempos, os museus assumiram papéis estratégicos no mundo "[...] marcado pela desconstrução das noções tradicionais de tempo e de espaço, no qual identidades locais e globais se relacionam em complementaridade." (INSTITUTO BRASILEIRO DE MUSEUS, 2012, p. 4).

A existência simultânea de museus tradicionais/concretos e museus em ambientes virtuais é marca do cenário artístico-cultural contemporâneo. Apesar da aproximação entre eles, no que permeia suas funções museológicas de preservar e de disponibilizar conteúdos informacionais, no campo das artes, o distanciamento arquitetônico e de acesso físico/presencial é latente. Baseado nos tipos arquitetônicos de museus descritos por Oliveira (2007), apresentamos, no Quadro 2, suas categorias, formas e tipos de acesso. Vale ressaltar que no ciberespaço, assim como nas arquiteturas tradicionais também existe uma arquitetura que se distingue entre si, entre modelos e formas.

Quadro 2 - Tipos arquitetônicos de museus

\begin{tabular}{|c|c|c|}
\hline Categoria & Formas & Acesso \\
\hline $\begin{array}{c}\text { Museu casa, } \\
\text { residência histórica }\end{array}$ & $90 \%$ do partido arquitetônico original. & Presencial \\
\hline $\begin{array}{c}\text { Edifício convertido } \\
\text { ou adaptado }\end{array}$ & $\begin{array}{c}\text { Estrutura antiga ou nova aproveitada para museu, com } \\
\text { bastante alteração no partido aquitetônico. }\end{array}$ & Presencial \\
\hline Edifício concebido & Criado especialmente para ser museu. & Presencial \\
\hline Museu ao ar livre & $\begin{array}{c}\text { Museu in situ, Museu jardim e Ecomuseu; Estruturas ao } \\
\text { ar livre. }\end{array}$ & Presencial \\
\hline
\end{tabular}


Fábio Rogério Batista Lima, Plácida Leopoldina Ventura Amorim da Costa Santos.

\begin{tabular}{|c|c|c|}
\hline Museu digital & $\begin{array}{c}\text { MD:apresenta interface presencial e estão on-line na } \\
\text { Web; Cybermuseu CM que funcionam apenas na Web }\end{array}$ & $\begin{array}{c}\text { Presencial e } \\
\text { Remoto }\end{array}$ \\
\hline Museu virtual & $\begin{array}{c}\text { Museu que advêm da concepção de Malraux e que pode } \\
\text { ser estendido em CD ROM, DVD e VHS, mas que se off- } \\
\text { line, não apresenta novidade no suporte apresentado. }\end{array}$ & Remoto \\
\hline Museum bus & Estrutura criada em um carro, com mobilidade. & Presencial \\
\hline Para-museus & Parques temáticos e zoológicos. Estruturas possíveis de \\
serem museus. & Presencial \\
\hline Webmuseu & $\begin{array}{r}\text { Ambientes informacionais com exposições de obras de } \\
\text { artes apresentadas virtualmente }\end{array}$ & Remoto \\
\hline
\end{tabular}

Fonte: Adaptado de Oliveira (2007, p. 13).

Os museus de artes modernizaram-se e utilizam-se das tecnologias disponíveis para a descrição, a apresentação e a divulgação de seus acervos que, cada vez mais estão sendo automatizados em seus serviços, com a digitalização de seus acervos e catálogos e, muitas vezes, já se apresentam construídos digitalmente para serem dispostos nas páginas da Web por meio de portais e websites, "[...] parece que a essência da tecnologia digital é a tradução da natureza em bits para produção de formatos comunicativos e conversacionais globais.” (LEMOS, 2009, doc. não paginado).

Nesse contexto, a disposição dos museus de arte para o uso das TIC tem permitido que seus catálogos possam ser vistos não só na forma impressa livro/inventário, mas também pela rede Internet, na forma de catálogos on-line, como também, em alguns casos, por visitas virtuais pela Web (LIMA, 2012; LIMA; SANTOS, 2014).

Neste sentido, o museu disponibiliza todo o seu acervo pela Web, não sendo necessário o deslocamento geográfico. Esse tipo de disponibilização oferece o acesso à informação, a visualização da representação de obras de arte àqueles que não têm condições de uma visita presencial e, ainda, prepara os usuários potenciais para uma visita presencial, fornecendo subsídios informacionais a respeito das obras expostas que geram curiosidade nos pretendentes na visita presencial. 
Fábio Rogério Batista Lima, Plácida Leopoldina Ventura Amorim da Costa Santos.

A ubiquidade nas artes hoje é uma realidade, visto que os grandes museus têm aplicativos que possibilitam a visitação virtual ao acervo por meio de dispositivos móveis.

Benjamin (1994), em seu ensaio, A obra de arte na era de sua reprodutibilidade técnica, escrito em 1936, referindo-se às técnicas de reprodução de obras de arte (pintura), nos mostra dois lados: um positivo e outro negativo. Por um lado, a obra de arte reproduzida, deixaria de ter seu caráter único (autêntico); a falta desse modo de ser aurático, segundo ele, provocaria um empobrecimento baseado na tradição (culto, magia, contemplação do belo), pois o simulacro esvazia a experiência. Contudo, por outro lado, suas imagens (reprodução das originais) passariam a fazer parte de uma camada massiva da sociedade, deixando-se desligar de uma elite cultural que outrora era exclusiva. Favoreceria, dessa forma, a socialização da cultura, da arte, levando a crítica e a reflexão às camadas antes desprovidas.

Dessa forma, Benjamin analisa a questão da autenticidade da obra em oposição ao seu simulacro em um mundo, no qual não falta demanda para consumo desses produtos reproduzidos. O suprassumo de sua análise e fundamento de sua crítica é a questão da perda da "aura" nas obras de arte pela reprodutibilidade técnica (LIMA, 2012, p. 35). Ele conceitua (aura) como sendo "[...] uma figura singular, composta de elementos espaciais e temporais: a aparição única de uma coisa distante, por mais perto que ela esteja [...]" (BENJAMIN, 1994, p. 170). O autor, referindo-se a reprodução da obra de arte diz:

A mais perfeita reprodução sempre falta alguma coisa: o hic et nunc da obra de arte, a unicidade de sua presença no próprio local onde ela se encontra. Não obstante, é a esta presença única, e somente a ela, que se encontra ligada toda sua história. (BENJAMIN, 2000, p. 224).

Benjamin esclarece em seu ensaio, que a reprodutibilidade técnica já acontecia muito antes da fotografia e do cinema. No entanto, evidencia-se um aumento exponencial da reprodução de imagens devido ao surgimento desses equipamentos reprodutores - como as fotografias, o cinema e, logo após, com o surgimento das fotocopiadoras a partir da década de sessenta (LIMA, 2012). 
Cada época possui seu método e instrumento de reprodução de imagem, e também, seu modo de cultuar suas obras imagéticas. Antes a arte estava a serviço de um ritual, inicialmente mágico, e depois religioso, reservada a poucos para contemplação. (LIMA, 2012, p. 35).

Contudo, tem havido um aumento exponencial nas reproduções de obras de arte por meio de máquinas digitalizadoras, e isso nem sempre oferece o acesso à fidelidade e às características da obra original.

Existem ambientes virtuais de visitação que possibilitam não apenas visualizar as obras, mas também interagir com elas, modificá-las, assistir a documentários a respeito do artista ou da exposição, ao mesmo tempo em que se navega pelo interior imersivo da página. Podemos ter, atualmente, experiências de ponte nos ambientes museológicos, experiências que se tornam experiências de mídias cruzadas. Tais experiências, segundo Resmini e Rosati (2011a, p. 54, tradução nossa) ligam “[...] múltiplas experiências em ponte conectadas a mídias, a ambientes e ecologia ubíqua, um processo único onde todas as partes contribuem para que o usuário tenha uma experiência global e sem emendas."

O termo experiência de ponte foi introduzido pela primeira vez, por Joel Grossman (2006) em um artigo para UX Matters. Para Resmini e Rosati (2011a, p. 18, tradução nossa), experiência de ponte é aquela “[...] em que a experiência do usuário abrange múltiplos canais de comunicações, gêneros, documento ou formatos de mídia para um propósito tático específico."

Atualmente, as experiências de ponte fazem parte de nosso dia a dia. Quando quisermos visitar um museu de artes, por exemplo, podemos, primeiramente, abrir a página do museu na Web, ver os dias e horários de funcionamento, telefonar ao museu para tirar alguma dúvida, ter acesso prévio às exposições disponíveis e, em muitos casos, até existe a possibilidade de fazer visitas virtuais, ao mesmo tempo em que podemos baixar aplicativos que servem como guias da exposição, fazer compras nas lojas virtuais do museu, tudo isso feito via celular e Internet. O tempo de interação do receptor com a informação quando conectado online, segundo Barreto (2008, doc. não paginado), 
Fábio Rogério Batista Lima, Plácida Leopoldina Ventura Amorim da Costa Santos.

[...] é em tempo real, com uma velocidade que o reduz ao entorno de zero. Esta velocidade de acesso junto com a possibilidade de uso coloca nova dimensão para o julgamento de valor da informação; o receptor passa a ser o julgador da sua relevância em tempo real, no momento de sua interação e não mais em uma condição de retro alimentação, isto é, no final do processo.

No tópico a seguir, faremos uma breve análise sobre o website do museu de artes Pinacoteca do estado de São Paulo e utilizaremos as heurísticas da AIP.

\section{Website do museu de artes Pinacoteca do Estado de São Paulo e heurísticas da Arquitetura Pervasiva}

Fundada em 1905, pelo governo do estado de São Paulo, a Pinacoteca é um museu de artes visuais com ênfase na produção brasileira do século XIX até a contemporaneidade.

Algumas formas que a Pinacoteca utiliza e dispõe na comunicação de seu acervo e serviços são: visita presencial, catálogos impressos, por meio de website e, mais recentemente, desde junho de 2014, existe uma nova forma de interlocução com o museu. Trata-se do aplicativo para dispositivos móveis ${ }^{2}$ que funciona com o sistema Android. O aplicativo foi construído em parceria com o Google Cultural Institute e mostra detalhes sobre as principais obras que compõem as exposições, textos explicativos e visitas virtuais narradas pelos curadores da Pinacoteca. Cada uma dessas formas têm suas especificidades, limitações e novos questionamentos.

Por questões geográficas, nos limitaremos a analisar somente o website do museu. Contudo, temos um conhecimento dos espaços internos na forma presencial, o qual utilizaremos como suporte de conhecimento de causa, a fim de fortalecer a análise como um todo. A Figura 1 retrata as formas que o museu utiliza para disponibilizar seu acervo. 

contemplação: imergindo na Pinacoteca do estado de São Paulo.

Fábio Rogério Batista Lima, Plácida Leopoldina Ventura Amorim da Costa Santos.

Figura 1 - Formas de disponibilização do acervo

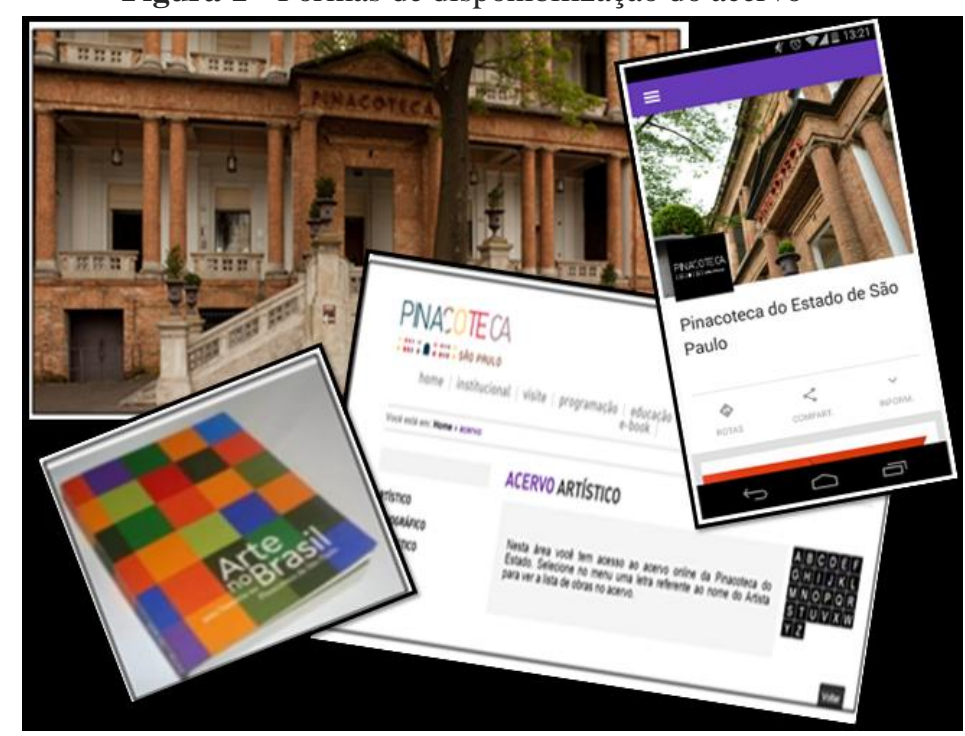

Fonte: Elaborado pelo autor.

A seguir, no Quadro 3, apresentamos uma breve análise do acesso às informações das obras de arte no website da Pinacoteca de São Paulo e utilizamos, como suporte teórico e conceitual, as heurísticas da AIP

Quadro 3 - Análise das heurísticas da AIP aplicadas ao website da Pinacoteca do Estado de São Paulo

\begin{tabular}{|l|l|}
\hline $\begin{array}{c}\text { Heurísticas da Arquitetura da } \\
\text { Informação Pervasiva }\end{array}$ & $\begin{array}{c}\text { Website da Pinacoteca do } \\
\text { Estado de São Paulo }\end{array}$ \\
\hline Status científico & Não contempla \\
\hline Ecologia informacional & Contempla \\
\hline Complexidade & Contempla \\
\hline Pervasividade & Contempla \\
\hline Ubiquidade & Contempla \\
\hline Everyware & Não contempla \\
\hline Place-making & Contempla \\
\hline Consistência & Contempla \\
\hline Resiliência & Não contempla \\
\hline Redução & Não contempla \\
\hline Correlação & Não contempla \\
\hline Interoperabilidade & Não contempla \\
\hline Semântica & Não contempla \\
\hline Acessibilidade & Contempla \\
\hline Usabilidade & Contempla \\
\hline Encontrabilidade & Contempla \\
\hline
\end{tabular}

Fonte: Elaborado pelo autor. 
Fábio Rogério Batista Lima, Plácida Leopoldina Ventura Amorim da Costa Santos.

De acordo com a análise das heurísticas da AIP aplicadas ao website do museu de artes visuais Pinacoteca apontadas no Quadro 3:

O Status científico não é contemplado porque o website do museu não se trata de uma disciplina ou algo que denote caráter teórico. A Ecologia informacional é contemplada no website, já que apresenta um conjunto de relações tanto de estruturas informacionais, estruturas tecnológicas, canais, dispositivos e quaisquer elementos pertencentes aos ambientes analógicos, digitais ou híbridos, quanto os instrumentos de acesso, como nos catálogos on-line.

A Complexidade também marca presença no website da Pinacoteca, por tratar-se de um ambiente cultural de resguarda e disponibilização da memória e da cultura de uma sociedade pela arte. Essa arte faz parte do acervo como recorte de um período, de um contexto, etc. Além disso, a Pervasividade também faz parte do website do museu, uma vez que podemos ter acesso às informações e aos conteúdos dos acervos disponibilizados pelo site por meio de uma infinidade de equipamentos tecnológicos que dão acesso à Internet. Junto a isso, soma-se a Ubiquidade do acesso às informações, por meio de estruturas da ecologia informacional.

Pode-se acessar, por exemplo, todo o acervo da Pinacoteca por meio de dispositivos moveis ligados à Internet. Everyware: o website não tem essa tecnologia que possibilita o processamento da informação dissolvida em meio aos comportamentos dos sujeitos. Por outro lado, o Website tem o que se conhece na AIP como Place-making, alojadas no site em forma de etiquetas, ícones autoexplicativos como programação, educação, acervo, os quais servem para orientar os usuários sobre o setor que ele estará adentrando no site, construindo sentido de localização na ecologia informacional complexa.

O website da Pinacoteca atende à sua finalidade, que é expor para a sociedade à herança cultural de um determinado contexto, nesse caso, a arte brasileira do século XIX, mantendo certa consistência contextual em seu acervo. Dentre as heurísticas analisadas, as quais o website analisado não contempla, estão a Resiliência, a Redução, a Correlação, a Interoperabilidade e a Semântica. Por outro lado, o site ainda permite que se tenha uma boa Acessibilidade, pois os ícones de acesso às paginas e às informações estão bem organizados, de 
Fábio Rogério Batista Lima, Plácida Leopoldina Ventura Amorim da Costa Santos.

forma que o usuário se sinta seguro e autônomo para navegar - Usabilidade. A Encontrabilidade também está presente no website da Pinacoteca, visto que o site apresenta mecanismos de busca eficientes que atendem às necessidades de recuperação da informação no ambiente específico de arte por meio dos nomes dos artistas.

Os elementos heurísticos apresentados estão alinhados à convergência que a Arquitetura da Informação Pervasiva exige. São sistemas integrados e complexos e que Resmini e Rosati (2011a) entendem ser maiores que a soma de suas partes que dependem fortemente dos relacionamentos entre as partes.

O fácil acesso as tecnologias informáticas, como, por exemplo, os dispositivos móveis (celulares e tablets) e a Internet de banda larga, proporcionou um terreno fértil para as ecologias informacionais complexas, o que gerou uma melhora na acessibilidade a ambientes informacionais, como os museus no ambiente virtual. Desta forma, a atuação do profissional da informação nesse território se faz cada vez mais necessária e presente nos trabalhos de representação e organização dos conteúdos.

\section{Conclusão}

As mídias que hoje nos dão acesso à informação, como, por exemplo, as mídias de comunicação, a exemplo da rede Internet, ganham corpo em equipamentos informáticos móveis, juntamente com a possibilidade de conexão à redes sem fio, e são consideradas por alguns autores como Santaella (2013), “[...] a tônica tecnológica do momento." Essas novas tecnologias dispõem de um tipo de comunicação ubíqua, pervasiva e ao mesmo tempo “[...] corporificada e multiplamente situada que está começando a se insinuar nos objetos cotidianos com tecnologia embarcada, a tão falada internet das coisas." (SANTAELLA, 2013, p. 15).

É nesse novo cenário, permeado por ecologias informacionais complexas que trabalhamos as questões referentes à preparação e adaptação dos museus para esse novo contexto. Percebemos, no entanto, que os museus, mais especificamente o museu analisado Pinacoteca do Estado de São Paulo, estão 
Fábio Rogério Batista Lima, Plácida Leopoldina Ventura Amorim da Costa Santos.

aderindo às novas exigências tecno-informacionais e somando as novas mídias interativas como forma de expansão. No entanto, ainda não há estudos metodológicos relacionados à práxis da Arquitetura da Informação aplicados ao universo museológico.

Sendo assim, concluímos que as heurísticas da Arquitetura da Informação Pervasiva podem servir de subsídio na práxis de futuras elaborações de Arquitetura da Informação Pervasiva direcionadas aos ambientes virtuais de contemplação das artes.

\section{Referências}

BARRETO, Aldo de Albuquerque. A aventura de perceber significados. DataGramaZero, Rio de Janeiro, v. 15, n. 3, jun. 2014.

BARRETO, Aldo de Albuquerque. Uma quase história da Ciência da Informação. DataGramaZero, Rio de Janeiro, v. 9, n. 2, abr. 2008.

BAUMAN, Zygmunt. Modernidade líquida. Rio de Janeiro: Zahar, 2003.

BENJAMIN, Walter. A obra de arte na era de sua reprodutibilidade técnica. In: BENJAMIN, Walter. Magia e técnica, arte e política: ensaios sobre literatura e história da cultura. São Paulo: Brasiliense, 1994. p. 165-196.

BENJAMIN, Walter. A obra de arte na era de sua reprodutibilidade técnica. In: ADORNO, Theodor Ludwig Wiesengrund et al. Teoria da cultura de massa. São Paulo: Paz e Terra, 2000.

DAVENPORT, T. H. Putting the enterprise into the enterprise system. Harvard business review, Brighton, v. 76, n. 4, 1998.

ECKERT-HOFF, Beatriz Maria. Apresentação e Editorial. Revista de Estudos de Tecnologia de Informação e Comunicações, Jundiaí, v. 1, n. 1, 2011.

CASTELLS, Manuel. A era da informação: economia, sociedade e cultura. São Paulo: Paz e Terra, 1999. (A sociedade em rede, 1).

CUNHA, Antônio Geraldo da. Dicionário etimológico da língua portuguesa [on-line]. Rio de Janeiro: Lexikon, 2007.

DAVENPORT, T. H. Putting the enterprise into the enterprise system. Harvard business review, Brighton, v. 76, n. 4, 1998. 
Fábio Rogério Batista Lima, Plácida Leopoldina Ventura Amorim da Costa Santos.

GROSSMAN, Joel. Designing for bridge experiences. San Francisco: UX Matters, 2006.

INSTITUTO BRASILEIRO DE MUSEUS. $\mathbf{1 0}^{\mathbf{a}}$ semana de museus: museus em um mundo em transformação: novos desafios, novas inspirações: de 14 a 20 de maio de 2012. 1 guia, Rio de Janeiro, 2012.

LACERDA, Flávia. Arquitetura da informação: aspectos epistemológicos, científicos e práticos. 2005. Dissertação (Mestrado em Ciência da Informação) Programa de Pós-Graduação em Ciência da Informação, Universidade de Brasília, Brasília, 2005.

LACERDA, Flávia. Arquitetura da Informação Pervasiva: projetos de ecossistemas de informação na Internet das Coisas. 2015. Tese (Doutorado em Ciência da Informação) - Programa de Pós-Graduação em Ciência da Informação, Universidade de Brasília, Brasília, 2005.

LEMOS, André. Nova esfera conversacional. In: MARQUES, Ângela et al. Esfera pública, redes e jornalismo. Rio de Janeiro: E-Papers, 2009, p. 9-30.

LIMA, Fábio Rogério Batista; SANTOS, Plácida Leopoldina Ventura Amorim da Costa. Museu e suas tipologias: o webmuseu em destaque. Informação e Sociedade, João Pessoa, v. 24, n. 2, p. 57-68, mai./ago. 2014.

LIMA, Fábio Rogério Batista. Imagem e tecnologia: webmuseu de arte. 2012. Dissertação (Mestrado em Ciência da Informação) - Programa de PósGraduação em Ciência da Informação, Universidade Estadual Paulista Júlio de Mesquita Filho, Marília, 2012.

LIMA-MARQUES, Mamede. Outline of a theoretical framework of Architecture of Information: a School of Brasilia proposal. In: BEZIAU, JeanYves; CONIGLIO, Marcelo Esteban (Org.). Logic without Frontiers. Festschrift for Walter Alexandre Carnielli on the occasion of his 60th birthday. London: College Publications, 2011.

LYYTINEN, Kalle; YOO, Youngjin. Issues and Challenges in Ubiquitous Computing. Communications of the ACM, New York, v. 45, n. 12, p. 63-96, 2002.

MCCAULEY, Kym. Information Architecture: Building to Have Clients or Having Clients to Build? Library Automated Systems Information Exchange, Melbourne, v. 32, n. 1, p. 7, abr. 2001.

MORVILLE, Peter; ROSENFELD, Louis. Information for architecture for the Word Wide Web. 3. ed. Sebastopol: O'Reilly, 2006. 
Fábio Rogério Batista Lima, Plácida Leopoldina Ventura Amorim da Costa Santos.

NETTO, Vinicius de Moraes. Entre espaços urbanos e digitais, ou o desdobramento da prática. Urbe: Revista Brasileira de Gestão Urbana, Curitiba, v. 3, n. 1, p. 11-26, 2011.

OLIVEIRA, S. L. Tratado de metodologia científica: projetos de pesquisas, TGI, TCC, monografias, dissertações e teses. 2. ed. São Paulo: Pioneira, 1997.

OLIVEIRA, Henry Poncio Cruz de. Arquitetura da informação pervasiva: contribuiçõos conceituais. 2014. Tese (Doutorado em Ciência da Informação) Programa de Pós-Graduação em Ciência da Informação Universidade Estadual Paulista Júlio de Mesquita Filho, Marília, 2014.

OLIVEIRA, José Cláudio. O museu digital: uma metáfora do concreto ao digital. Comunicação e Sociedade, Braga, v. 12, p. 147-161, 2007.

RESMINI, Andrea; ROSATI, Lucas. Pervasive information architecture: designing crosschannel user experiences. Burlington: Elsevier, 2011a.

RESMINI, Andrea; ROSATI, Lucas. A Brief History of Information Architecture. Journal of Information Architecture, Copenhagen, v. 3, n. 2, p. 33-46, $2011 b$.

SÁEZ VACAS, F. Contextualización sociotécnica de la web 2.0. In.: FUMERO, A.; ROCA, G. Web 2.0. Madrid: Fundação Orange, 2007.

SANTAELLA, Lucia. Comunicação ubíqua: repercussões na cultura e na educação. São Paulo: Paulus, 2013.

SANTAELLA, Lucia. Linguagens líquidas na era da mobilidade. São Paulo: Paulus, 2007.

SANTOS, Plácida Leopoldina Ventura Amorim da Costa; VIDOTTI, Silvana Aparecida Borsetti Gregorio. Perspectivismo e tecnologias da informação e comunicação: acréscimos à Ciência da Informação? DataGramaZero, Rio de Janeiro, v. 10, n. 3, jun. 2009.

SOUZA, Marckson Roberto Ferreira de; PÁDUA, Mariana Cantisani. Arquitetura da Informação Pervasiva: desvendando as heurísticas de Resmini e Rosati. Informação \& Tecnologia, Marília, v. 1, n. 1, jan./jun. 2014.

WEISSBERG, Jean-Louis. Paradoxo da teleinformática. In: PARENTE, André (Org.). Tramas da rede. Porto Alegre: Sulina, 2004. p. 113-141.

WEITZMAN, Louis Murray. The architecture of information: interpretation and presentation of information in dynamic environments. 1995. Tese (Doutorado) - Massachusetts Institute of Technology, Massachusetts Institute Of Technology, Cambridge, 1995. 


\title{
The ubiquity of arts in virtual environments of contemplation: immersing in the Pinacoteca of São Paulo
}

\begin{abstract}
The continuous technological changes directly affect labor relations, family, community, in which the place and space stop being concrete and absolute and become, according to Zygmunt Bauman, "liquids and relatives". This article aims to study the Pinacoteca arts museum of São Paulo based on the heuristics of the Pervasive Information Architecture (AIP). The research is theoretical, descriptive and exploratory, and was based on the qualitative systematic observation of the collected bibliography. As a result, we conclude that the heuristics Architecture of Pervasive Information (API) can provide support in the praxis for future elaborations of Architecture of Pervasive Information directed to virtual environments of contemplation of arts.
\end{abstract}

Keywords: Museum. Architecture of Information. Pervasive Information Architecture (AIP). Ubiquity. Heuristics.

Recebido em: 09/02/2017

Aceito em: 29/06/2017

${ }^{1} \mathrm{O}$ “[...] ambiente informacional híbrido é um espaço de ressignificação permanente onde o usuário é o principal agente [...]" (SOUZA; PÁDUA, 2014, p. 69).

2 Dispositivos móveis "[...] são definidos como quaisquer equipamentos ou periféricos que podem ser transportados com informação que fique acessível em qualquer lugar." (SANTAELLA, 2013, p. 248). 